\title{
Exaggerated pressor response in relation to attenuated muscle temperature response during contraction in ischemic heart failure
}

\author{
Jianhua $\mathrm{Li}^{1,2}{ }^{*}$, Zhaohui Gao ${ }^{1,2}$, Jian Lu ${ }^{1,2}$ and Jihong Xing ${ }^{1,2}$ \\ 1 Heart and Vascular Institute, Milton S. Hershey Medical Center, Pennsylvania State University College of Medicine, Hershey, PA, USA \\ ${ }^{2}$ Department of Medicine, Milton S. Hershey Medical Center, Pennsylvania State University College of Medicine, Hershey, PA, USA
}

Edited by:

Paul J. Fadel, University of Missouri, USA

\section{Reviewed by:}

Masaki Mizuno, University of Texas Southwestern Medical Center, USA Thad Wilson, Ohio University Heritage College of Osteopathic Medicine, USA

\section{*Correspondence:}

Jianhua Li, Heart and Vascular Institute H047, Milton S. Hershey Medical Center, Penn State College of Medicine, 500 University Drive, Hershey, PA 17033, USA.

e-mail: jz110@psu.edu
It is known that muscle temperature $\left(T_{\mathrm{m}}\right)$ increases with exercise. The purpose of this study was to examine if contraction-induced increase in $T_{\mathrm{m}}$ was altered in rats with heart failure (HF) induced by chronic myocardial infraction (MI) as compared with healthy control animals. A temperature probe was inserted in the triceps surae muscle to continuously measure $T_{\mathrm{m}}$ throughout experiments. Static muscle contraction was induced by electrical stimulation of the sciatic nerve for $1 \mathrm{~min}$. As baseline $T_{\mathrm{m}}$ was $34^{\circ} \mathrm{C}$, contraction increased temperature by $1.6 \pm 0.18^{\circ} \mathrm{C}$ in nine health control rats and by $1.0 \pm 0.15^{\circ} \mathrm{C}$ in $10 \mathrm{Ml}$ rats $(P<0.05$ vs. control). Note that there were no differences in developed muscle tension and muscle weight between the two groups. In addition, muscle contraction increased mean arterial pressure by $23 \pm 3 \mathrm{mmHg}$ in control rats and by $31 \pm 3 \mathrm{mmHg}$ in $\mathrm{Ml}$ rats $(P<0.05$ vs. control). A regression analysis further shows that there is an inverse liner relationship between the pressor response and static contraction-induced increase in $T_{\mathrm{m}}$. Our data suggest that $T_{m}$ increase evoked by contraction is impaired in $\mathrm{Ml}$ rats. The abnormal alteration in $T_{\mathrm{m}}$ likely modifies the reflex cardiovascular responses in $\mathrm{Ml}$ via mechanisms of temperature-sensitive receptors on muscle afferent nerves.

\section{INTRODUCTION}

The sympathetic nervous system is activated during exercise (Mark et al., 1985; Victor et al., 1988; Sinoway et al., 1989; Matsukawa et al., 1990). This contributes to increases in blood pressure, heart rate (HR), myocardial contractility, and peripheral vasoconstriction (Coote et al., 1971; McCloskey and Mitchell, 1972; Mitchell et al., 1977; Lind, 1983). Two mechanisms of neural control contribute to these exercise responses: "central command" and "the exercise pressor reflex" (Goodwin et al., 1972; Mitchell et al., 1983; Waldrop et al., 1996). Central command is a mechanism whereby signals from a central site responsible for recruiting motor units activate cardiovascular control areas in the brain stem (Goodwin et al., 1972; Waldrop et al., 1996). The exercise pressor reflex is a mechanism whereby signals from thin-fiber skeletal muscle group III (predominately mechanically sensitive) and group IV (predominately metabolically sensitive) afferents likewise evoke increases in blood pressure and HR via coordinated changes in autonomic outflow (Kaufman et al., 1983; Mitchell et al., 1983; Kaufman and Forster, 1996). This system responds to mechanical deformation of the muscle afferent receptive field (i.e., "mechanoreceptor" stimulation) as well as to metabolic stimulation (i.e., "metaboreceptor" stimulation). When these receptors are stimulated, thin-fiber muscle afferent nerves are engaged, cardiovascular circuits in the brain stem are activated, sympathetic activity increases, and blood pressure rises (Mitchell et al., 1983).

The sympathetic nerve and blood pressure responses to exercise are exaggerated in heart failure (HF; Middlekauff et al., 2000,
2001; Li et al., 2004b; Momen et al., 2004; Gao et al., 2007). However, the underlying mechanisms to cause the abnormal autonomic responses are poorly understood.

In general, purinergic P2X receptors and transient receptor potential vanilloid type 1 (TRPV1 or VR1) are widely found on thin-fiber afferent nerves (Guo et al., 1999; Ma, 2002) and mediates numerous sensory afferent activations (Caterina et al., 1997; Nault et al., 1999; Smith and McQueen, 2001; Zahner et al., 2003). Specifically, it has been reported that activation of P2X receptors on the nerve endings of muscle afferents plays a role in mediating the autonomic adjustments to active muscle (Hanna et al., 2002; Li and Sinoway, 2002; Hanna and Kaufman, 2003, 2004). Although TRPV1 has been reported to play little role in mediating the cardiovascular responses to activation of muscle afferent (Kindig et al., 2005), capsaicin, a TRPV1 agonist injected into the arterial supply of the hindlimb muscles evokes increases in blood pressure and HR (Li et al., 2004a,b; Smith et al., 2005).

Furthermore, abnormal responses of P2X and TRPV1 have been observed in rats with HF. For instance, previous studies have demonstrated that muscle afferent-mediated pressor response of P2X activation is exaggerated in HF animals and the responsiveness is related to the degree of left ventricular dysfunction ( $\mathrm{Li}$ et al., 2004b; Gao et al., 2007). The augmented reflex response is likely linked to upregulated P2X receptors in the sensory neurons of thin-fiber afferent nerves in HF (Gao et al., 2007; Wang et al., 2010). In addition, less TRPV1 expression is found in the sensory neurons of HF rats compared with control animals, and the 
pressor response of TRPV1 activation is attenuated in HF (Li et al., 2004b; Smith et al., 2005; Wang et al., 2010).

Muscle temperature $\left(T_{\mathrm{m}}\right)$ rises in exercising muscles (Shellock et al., 1985; Kenny et al., 2003), and P2X and TRPV1 are sensitive to change of temperature (Garcia-Villalon et al., 1997; Wang et al., 2003; Kluess et al., 2005). Thus, it was necessary to study contraction-induced increase in $T_{\mathrm{m}}$ in order to better understand heightened sympathetic activity in HF, likely due to P2X and TRPV1. Moreover, the published data have demonstrated that blood pressure response to stimulation of $\mathrm{P} 2 \mathrm{X}$ receptors on muscle afferents is attenuated with increasing $T_{\mathrm{m}}$ (Gao et al., 2006). This result suggests that higher $T_{\mathrm{m}}$ blunts effects of $\mathrm{P} 2 \mathrm{X}$ on the reflex pressor response. Likewise, lower $T_{\mathrm{m}}$ augments effects of $\mathrm{P} 2 \mathrm{X}$. In contrast, higher temperature increases its response as TRPV1 is activated (Caterina et al., 1997). Given that P2X is increased and TRPV1 is decreased after induction of myocardial infraction (MI; Smith et al., 2005; Gao et al., 2007), we hypothesized that contraction-induced increase in $T_{\mathrm{m}}$ is attenuated in HF rats and then abnormal $T_{\mathrm{m}}$ response in HF may affect the muscle pressor reflex via temperature-sensitive P2X and TRPV1 (Garcia-Villalon et al., 1997; Wang et al., 2003; Kluess et al., 2005). Moreover, a relationship between the reflex pressor response and $T_{\mathrm{m}}$ response during contraction was further determined in this report.

\section{MATERIALS AND METHODS CORONARY ARTERY LIGATION}

All procedures outlined in this study were approved by the Animal Care Committee of this institution. Sprague Dawley male rats $(150-180 \mathrm{~g})$ were anesthetized by inhalation of isoflurane oxygen mixture $(2-5 \%$ isoflurane in $100 \%$ oxygen), intubated, and artificially ventilated. A left thoracotomy between the fourth and fifth ribs was performed, exposing the left ventricular wall. The left coronary artery was ligated. Experiments were performed 610 weeks after coronary ligation. Age- and body weight-matched rats served as controls.

Transthoracic echocardiography was performed 1-2 weeks before the experiments. The rats were anesthetized by inhalation of isoflurane oxygen mixture $(2-5 \%$ isoflurane in $100 \%$ oxygen). The transducer was positioned on the left anterior chest, and left ventricular dimensions were measured. The fractional shortening (FS) was determined by echocardiographic measurements. FS is $>40 \%$ in controls $(n=9)$ and $<30 \%$ in $\operatorname{HF}(n=10)$, respectively.

\section{EXPERIMENTAL PREPARATION}

The rats were anesthetized by inhalation of isoflurane oxygen mixture (2-5\% isoflurane in $100 \%$ oxygen). An endotracheal tube was inserted into the trachea and attached to a ventilator. Polyethylene catheters (PE-50) were inserted into the common carotid artery and external jugular vein for measurement of arterial blood pressure and for fluid administration, respectively. The skin covering the triceps surae muscle and femoral region was surgically separated from the muscle below in order to eliminate inputs from cutaneous afferents in the hindlimb. The sciatic nerve of each leg was isolated and then placed on a stimulating electrode. A needle microprobe connected to a thermometer (Model BAT-12, World
Precision Instrument, Sarasota, FL, USA) was directly inserted into the gastrocnemius muscle of the hindlimb to continuously monitor baseline $T_{\mathrm{m}}$ throughout experiments and measure $T_{\mathrm{m}}$ responses to muscle contraction. The animals were ventilated, and tidal $\mathrm{CO}_{2}$ was monitored by a respiratory gas monitor (DatexOhmeda, Madison, WI, USA) and maintained within normal ranges, as previously described (Li et al., 2004a,b; Gao et al., 2007). Body temperature was maintained between 36.5 and $38.5^{\circ} \mathrm{C}$ by a heating pad and external heat lamps, and fluid balance was stabilized by a continuous infusion of saline.

Decerebration was performed as previously described (Li et al., 2004a,b; Smith et al., 2005; Gao et al., 2007). A transverse section was made anterior to the superior colliculus. Once this procedure was completed, anesthesia was removed from the inhaled mixture. A recovery period of $60 \mathrm{~min}$ after decerebration was employed to allow sufficient time for elimination of the effects of anesthesia gas from the preparation.

Arterial blood pressure was measured by connecting the carotid arterial catheter to a pressure transducer (model P23ID, Statham). Mean arterial pressure (MAP) was obtained by integrating the arterial signal with a time constant of $4 \mathrm{~s}$. HR was determined from the arterial pressure pulse. All measured variables were continuously recorded on an eight-channel chart recorder (model TA 4000, Gould, Valley View, OH, USA) and stored on a PC computer that used the PowerLab system (ADInstruments, Castle Hill, Australia). The triceps surae muscle was isolated and the calcaneal bone of the hindlimb was cut. The Achilles tendon was connected to a force transducer for the measurement of muscle tension during electrically induced muscle contraction. The pelvis was stabilized in a spinal unit and the knee joints were secured by clamping the patellar tendon to a spinal unit.

On completion of each experiment, a 2-Fr microMillar pressure transducer catheter (Millar Instruments) was inserted into the right carotid artery and threaded into the left ventricle for measurement of left ventricular end-diastolic pressure (LVEDP). The heart was exercised after intravenous injection of an overdose of sodium pentobarbital $(120 \mathrm{mg} / \mathrm{kg}$ body weight) followed by $2 \mathrm{ml}$ of a saturated solution of potassium chloride. Wet heart and triceps surae muscle weight were measured. The data collected from rats whose left ventricle FS was $<30 \%$ were included in MI group of this report.

\section{EXPERIMENTAL PROTOCOLS}

A $60 \mathrm{~min}$ equilibration period was allowed after completion of experimental procedure. Contractions induced by electrical stimulation of the sciatic nerve were then performed in nine healthy control rats and $10 \mathrm{MI}$ rats. Static contraction of the triceps surae muscle was conducted at frequencies of $30 \mathrm{~Hz}$ (2.5 times motor threshold and $0.1 \mathrm{~ms}$ duration; Gao et al., 2006). Stimulation was sustained for $1 \mathrm{~min}$. Baseline $T_{\mathrm{m}}$ was controlled at 30,34 , and $38^{\circ} \mathrm{C}$ at a random way, respectively, by using a water-perfused heating pad and an ice bag around the hindlimb muscle. Contraction was performed at different baselines of $T_{\mathrm{m}}$. There was a $60 \mathrm{~min}$ rest period between each bout of contraction. The $T_{\mathrm{m}}$ was measured before, during, and after each of stimulations. Body core temperature 
and $T_{\mathrm{m}}$ on the contralateral leg were also measured during stimulation.

\section{DATA ACQUISITION AND ANALYSES}

Arterial blood pressure and developed muscle tension during muscle contraction were recorded on a PC computer that used Power Lab software. $T_{\mathrm{m}}$ was recorded on a temperature monitor. Control values were determined by averaging at least $1 \mathrm{~min}$ of the data immediately before the interventions. The peak change of each variable was determined by the peak response from control.

Peak change data for each variable were analyzed with a twoway ANOVA. Changes in temperature during 1 min-stimulation in control rats and MI rats were also analyzed with a two-way ANOVA. Tukey post hoc analyses were utilized to determine differences between groups, as appropriate. All values were expressed mean $\pm S E$. For all analyses, differences were considered significant at $P<0.05$. All statistical analyses were performed using SPSS for windows version 13.0

\section{RESULTS}

Rats with the left ventricular FS $<30 \%$ showed increases in heart weight, LVEDP, and left ventricular diastolic dimension (Table 1). These rats were used as a MI group. In addition, there were no significant differences in resting $T_{\mathrm{m}}$ and core body temperature as well as body and muscle weight between control and MI groups (Table 2).

\section{$T_{M}$ RESPONSE IN CONTROL AND MI RATS}

Following a start of electrical stimulation of the sciatic nerve, $T_{\mathrm{m}}$ increased. The response gradually returned to a steady level after the end of stimulation. At baseline $T_{\mathrm{m}}$ of 30,34 , and $38^{\circ} \mathrm{C}$, time courses of contraction-induced increase in $T_{\mathrm{m}}$ during $1 \mathrm{~min}$ of contraction are shown in Figures 1A-C. Peak temperature responses to contraction in control rats and MI rats are shown in Figure 1D. It is noted that an increase in $T_{\mathrm{m}}$ was significantly attenuated in MI rats compared with control rats, as resting $T_{\mathrm{m}}$ was 30 and $34^{\circ} \mathrm{C}$. However, this effect wasn't observed, as resting

Table 1 | Echocardiographic and cardiac characteristics.

\begin{tabular}{llllllll}
\hline & LVAW $(\mathbf{c m})$ & LVDD $(\mathbf{c m})$ & LVPW $(\mathbf{c m})$ & LVSD $(\mathbf{c m})$ & FS (\%) & Heart weight (g) & LVEDP $(\mathbf{m m H g})$ \\
\hline Control $(n=9)$ & $0.14 \pm 0.01$ & $0.89 \pm 0.01$ & $0.15 \pm 0.01$ & $0.40 \pm 0.02$ & $55.32 \pm 2.14$ & $1.42 \pm 0.02$ & $0.4 \pm 0.18$ \\
HF $(n=10)$ & $0.08 \pm 0.00^{*}$ & $1.09 \pm 0.02^{*}$ & $0.16 \pm 0.01$ & $0.87 \pm 0.02^{*}$ & $19.74 \pm 1.33^{*}$ & $1.79 \pm 0.04^{*}$ & $15 \pm 3.00^{*}$
\end{tabular}

LVAW, the thickness of left ventricular anterior wall; LVDD, left ventricular end-diastolic dimension; LVPW, left ventricular posterior wall; LVSD, left ventricular end-systolic dimension; FS, shortening fraction of LV; LVEDP, LV end-diastolic pressure. Values are mean $\pm S E$. ${ }^{*}$ indicates, $P<0.05$, vs. control.
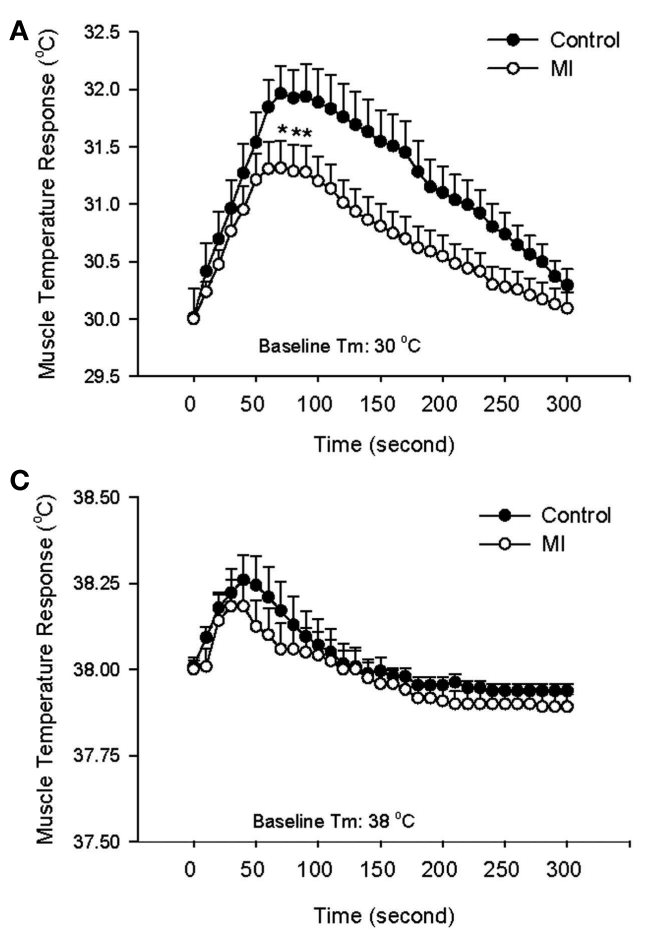

FIGURE 1 | Contraction-induced increase in muscle temperature $\left(T_{\mathrm{m}}\right)$ in control rats and $\mathrm{MI}$ rats during $1 \mathrm{~min}$ electrical stimulation of sciatic nerve and $4 \mathrm{~min}$ follow-up at different basal $T_{\mathrm{m}}: 30^{\circ} \mathrm{C}(\mathrm{A}), 34^{\circ} \mathrm{C}(\mathrm{B})$, and $\mathbf{3 8}^{\circ} \mathbf{C}$ (C). The peak temperature changes in the muscle during static
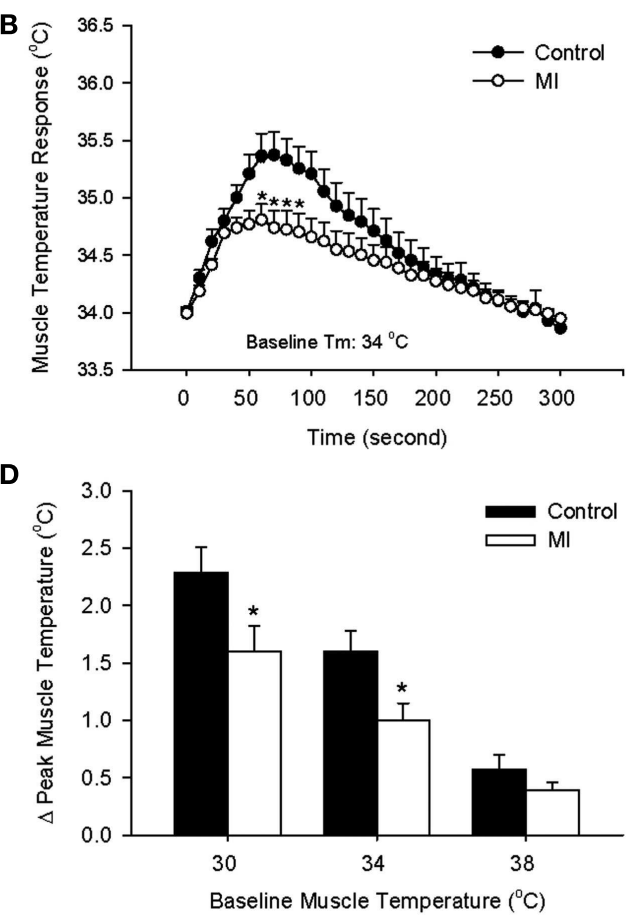

contraction at three levels of basal $T_{\mathrm{m}}$ are shown in (D). Values are means \pm SE (Control: 9 rats; $\mathrm{Ml}: 10$ rats). The increases in $T_{\mathrm{m}}$ during contraction were significantly lower in $\mathrm{Ml}$ at baseline $T_{\mathrm{m}}$ of $30,34^{\circ} \mathrm{C}$. ${ }^{*} P<0.05$, compared with healthy control group. 
Table 2 | Muscle characteristics.

\begin{tabular}{|c|c|c|c|c|c|c|}
\hline & $\begin{array}{l}\text { Number } \\
\text { of rats }\end{array}$ & $\begin{array}{l}\text { Body weight } \\
\text { (BW, g) }\end{array}$ & $\begin{array}{l}\text { Muscle weight } \\
(\mathrm{MW}, \mathrm{g})\end{array}$ & $\begin{array}{l}\text { MW/BW } \\
(\mathrm{mg} / \mathrm{g})\end{array}$ & $\begin{array}{l}\text { Basal body } \\
\text { temperature }\left({ }^{\circ} \mathrm{C}\right)\end{array}$ & $\begin{array}{l}\text { Basal muscle } \\
\text { temperature }\left({ }^{\circ} \mathrm{C}\right)\end{array}$ \\
\hline Control & 9 & $535 \pm 19.4$ & $3.69 \pm 0.081$ & $6.9 \pm 0.1$ & $36.83 \pm 0.20$ & $34.50 \pm 0.16$ \\
\hline $\mathrm{HF}$ & 10 & $515 \pm 9.28$ & $3.67 \pm 0.078$ & $7.1 \pm 0.1$ & $36.99 \pm 0.14$ & $34.43 \pm 0.11$ \\
\hline
\end{tabular}

Muscle indicates the triceps surae muscle. Values are mean \pm SE. There are no differences in all parameters between the two groups.

Table 3 | Baseline MAP (mm Hg) and HR (beats/min), and peak responses.

\begin{tabular}{llllll}
\hline $\begin{array}{l}\text { Baseline } \\
\boldsymbol{T}_{\mathbf{m}}\end{array}$ & Groups & $\begin{array}{l}\text { Baseline } \\
\text { MAP }\end{array}$ & $\begin{array}{l}\text { Peak } \\
\text { MAP }\end{array}$ & $\begin{array}{l}\text { Baseline } \\
\text { HR }\end{array}$ & $\begin{array}{l}\text { Peak } \\
\text { HR }\end{array}$ \\
\hline $30^{\circ} \mathrm{C}$ & Control & $80 \pm 3$ & $99 \pm 4^{*}$ & $390 \pm 13$ & $410 \pm 13$ \\
& HF & $84 \pm 5$ & $119 \pm 6^{*}$ & $399 \pm 16$ & $423 \pm 17$ \\
$34^{\circ} \mathrm{C}$ & Control & $94 \pm 6$ & $117 \pm 7^{*}$ & $390 \pm 23$ & $414 \pm 25$ \\
& HF & $93 \pm 6$ & $124 \pm 7^{*}$ & $418 \pm 20$ & $443 \pm 20$ \\
$38^{\circ} \mathrm{C}$ & Control & $88 \pm 7$ & $109 \pm 11^{*}$ & $400 \pm 16$ & $406 \pm 17$ \\
& HF & $94 \pm 6$ & $114 \pm 8^{*}$ & $422 \pm 20$ & $432 \pm 24$
\end{tabular}

Values are means $\pm S E$. The number of animals $=9$ in control; and 10 in HF. MAP, mean arterial pressure; $H R$, heart rate; $T_{m}$, muscle temperature. There are no significant differences among basal values. ${ }^{*} P<0.05$, versus baseline.

$T_{\mathrm{m}}$ was $38^{\circ} \mathrm{C}$. Body core temperature and $T_{\mathrm{m}}$ on the contralateral leg were not significantly changed during stimulation.

\section{CARDIOVASCULAR RESPONSES IN CONTROL AND MI RATS}

Baseline MAP values before contraction were not different in the healthy control animals and the MI rats (Table 3). Electrical stimulation of the sciatic nerve significantly increased MAP in both groups. A greater MAP increase was observed in MI rats, as baseline $T_{\mathrm{m}}$ was 30 and $34^{\circ} \mathrm{C}$ but not $38^{\circ} \mathrm{C}$ (Figure $2 \mathrm{~A}$ ). There was no significant difference in HR response to the stimulation (Table 3 ).

It is noted that there were no significant differences in the muscle tension indicated by time-tension index in the two groups (Figure 2B). This suggests that attenuated $T_{\mathrm{m}}$ and enhanced pressor responses to contraction in the MI rats were not due to development of muscle tension. In addition, absolute muscle tensions appeared to be smaller in MI rats; however, no significant differences were observed in both groups. When baseline $T_{\mathrm{m}}$ was 30,34 , and $38^{\circ} \mathrm{C}$, peak tensions were $0.55 \pm 0.04,0.57 \pm 0.06$, and $0.46 \pm 0.04 \mathrm{~kg}$ in control; and $0.52 \pm 0.03,0.51 \pm 0.02$, and $0.44 \pm 0.03 \mathrm{~kg}$ in $\mathrm{MI}(P>0.05$, vs. control at all conditions $)$.

\section{A RELATIONSHIP BETWEEN PRESSOR AND $\boldsymbol{T}_{\mathrm{M}}$ RESPONSE}

Changes in MAP response to static muscle contraction were plotted against contraction-induced increase in $T_{\mathrm{m}}$. A significant inverse correlation was seen between the pressor response and increased $T_{\mathrm{m}}$ during contraction (Figure 3 ). Thus, the greater pressor response is likely linked to the lower $T_{\mathrm{m}}$ response in rats with MI.

\section{DISCUSSION}

Our data demonstrate that contraction-induced increase in $T_{\mathrm{m}}$ is attenuated in MI rats compared with control rats. A regression
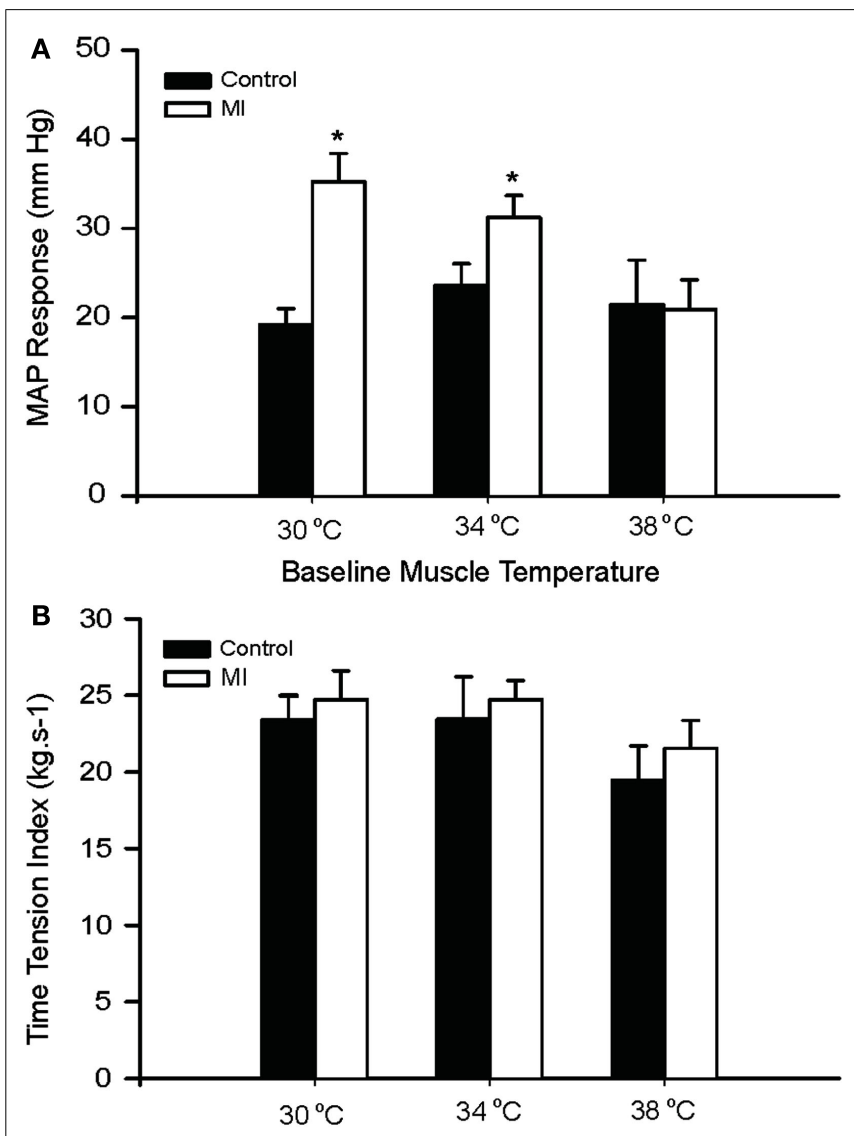

Baseline Muscle Temperature

FIGURE 2 | Peak pressor response and developed muscle tension evoked by sciatic nerve stimulation at three different basal $T_{m}: 30,34$, and $38^{\circ} \mathrm{C}$ in control and $\mathrm{MI}$ rats. (A) MAP responses were significantly augmented during static muscle contraction in $\mathrm{Ml}$ group at baseline $T_{\mathrm{m}}$ of 30 and $34^{\circ} \mathrm{C}$. (B) Developed tensions are indicated by time-tension index (TTI), and the TTI induced by static contraction were similar in two groups. ${ }^{*} P<0.05$, compared with healthy control group. The number of rats $=9$ in control; and 10 in $\mathrm{Ml}$.

analysis further shows that the lower $T_{\mathrm{m}}$ response is closely related to the greater pressor response during contraction. Notably, there are no differences in the muscle tension development and muscle mass in the control rats and rats with HF. This suggests that altered $T_{\mathrm{m}}$ and pressor responses in HF are unlikely due to muscle tension and/or muscle mass. Additionally, body core temperature is unchanged during contraction, indicating that body temperature is unlikely to affect the $T_{\mathrm{m}}$ and pressor responses. Thus, 


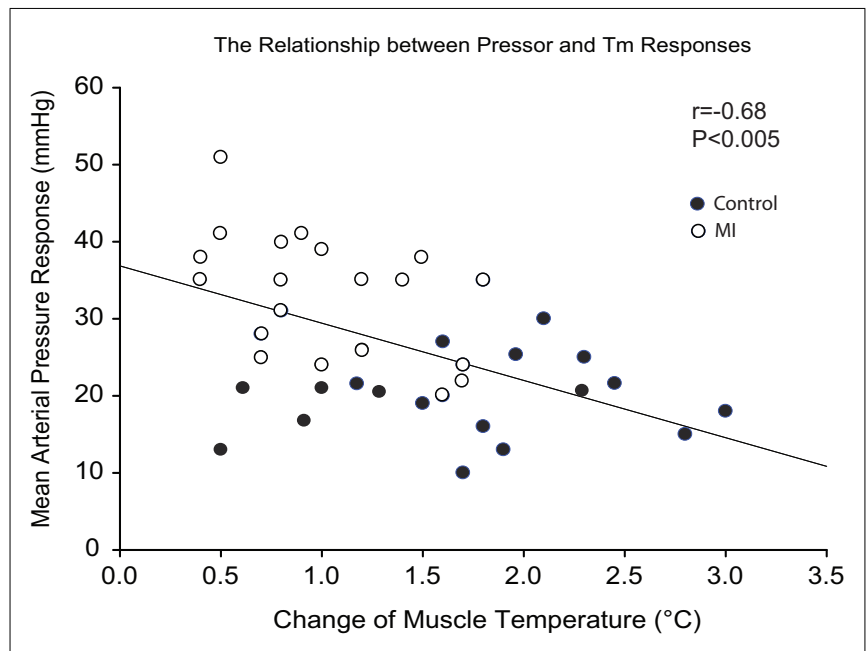

FIGURE 3 | Regression analyses between MAP response and muscle temperature change during static contraction at baseline $T_{\mathrm{m}}$ of $\mathbf{3 0}$ and $34^{\circ} \mathbf{C}$. Note that a higher MAP response was seen as a lower $T_{m}$ was induced by muscle contraction.

findings of this study suggest that impaired $T_{\mathrm{m}}$ response is likely responsible for the exaggerated muscle pressor reflex in $\mathrm{HF}$.

\section{EFFECTS OF SENSORY NERVES' P2X AND TRPV1 ON MUSCLE PRESSOR REFLEX}

Evidence supports that ATP sensitive P2X receptors play a role in evoking mechano- and metaboreceptors mediated stimulation of the exercise pressor reflex (Hanna et al., 2002; Li and Sinoway, 2002; Hanna and Kaufman, 2003, 2004). In HF, P2X plays a role in sympathetic abnormalities by demonstrating that the muscle pressor response induced by $\alpha, \beta$-me ATP injected into rat hindlimb muscles is exaggerated in HF animals (Gao et al., 2007). Also, P2X receptor-mediated muscle mechanoreceptor contribution to the sympathetic nerve response to exercise is augmented in $\mathrm{HF}$ ( $\mathrm{Li}$ et al., 2004b; Wang et al., 2010). Moreover, the greater response to activation of PX receptor is related to the severity of left ventricular dysfunction (Gao et al., 2007). This may be due to that HF induces upregulation of $\mathrm{P} 2 \mathrm{X}$ receptors in the sensory neurons (Gao et al., 2007). However, the intrinsic mechanism responsible for the P2X receptor alternations in rats with $\mathrm{HF}$ is unclear.

It has been reported that $\mathrm{P} 2 \mathrm{X}$ receptors are temperaturesensitive and P2X activity increases as temperature falls (GarciaVillalon et al., 1997; Ziganshin et al., 2002; Kluess et al., 2005). The effect of $\mathrm{P} 2 \mathrm{X}$ receptor on reflex muscle response has recently been reported to be sensitive to alternations of $T_{\mathrm{m}}$ (Gao et al., 2006). This prior study further suggests that elevated $T_{\mathrm{m}}$ attenuates the pressor response to static muscle contraction.

Result of the present study shows that $T_{\mathrm{m}}$ and pressor responses during contraction tended to be smaller in both healthy and MI rats as baseline $T_{\mathrm{m}}$ was set at $38^{\circ} \mathrm{C}$. Moreover, the greater pressor response was linearly related to the lower $T_{\mathrm{m}}$ response. This is consistent with the concept that the effect of $\mathrm{P} 2 \mathrm{X}$ receptor on reflex muscle response is sensitive to alternations of $T_{\mathrm{m}}$ and that elevated temperature attenuates the response (Gao et al., 2006). In addition, our data also show that an increase in $T_{\mathrm{m}}$ during contraction was attenuated in HF rats compared with control rats. Thus, the enhanced P2X activity and exaggerated muscle reflex in $\mathrm{HF}$ is likely attributed to a lower $T_{\mathrm{m}}$ response.

Metabolite sensitive-TRPV1 receptors have been reported to respond to heating (Wang et al., 2003). In this report, a rise in $T_{\mathrm{m}}$ in contracting muscle was smaller in the MI rats than in the controls. Thus, we postulate that the muscle metaboreflex is blunted by less stimulation of TRPV1 due to lower temperature response in HF. A lower $T_{m}$ in HF is likely to contribute to the attenuated TRPV1 activities. It has previously been reported that TRPV1 of sensory neurons is downregulated and TRPV1 response is attenuated in HF rats (Li et al., 2004b; Smith et al., 2005; Wang et al., 2010). Data of the present report provide further evidence that suggest that abnormal autonomic adjustments to exercise may be due to abnormalities in $T_{\mathrm{m}}$ response in HF. We believe that in HF mechanoreceptor contribution to muscle sympathetic nerve activity is augmented, whereas metaboreceptor engagement is attenuated. Overall, mechanosensitive afferents may contribute to a greater degree and muscle sympathetic response is exaggerated in HF (Sterns et al., 1991; Middlekauff et al., 2000, 2001; Li et al., 2004b; Momen et al., 2004; Smith et al., 2005).

\section{MUSCLE TEMPERATURE AND MUSCLE PRESSOR REFLEX}

It is known that $T_{\mathrm{m}}$ rises with exercise (Shellock et al., 1985; Kenny et al., 2003). During exercise, $T_{\mathrm{m}}$ observed in HF patients is abnormal as compared with healthy subjects (Shellock et al., 1985). Cold temperature increases cardiac demand in response to exercise and significantly reduces maximal exercise capacity in patients with HF (Juneau et al., 2002). A further study suggests that warming of exercising legs improves exercise capacity in patients with cardiac disease and low exercise tolerance (Yamanouchi et al., 1996).

An elevation of $T_{\mathrm{m}}$ by heating muscles increases reflex blood pressure and sympathetic nerve responses to exercise and cooling muscle delays those reflex activities (Ray and Gracey, 1997; Ray et al., 1997). It is noted that $T_{\mathrm{m}}$ is increased $>4^{\circ} \mathrm{C}$ and decreased $>7^{\circ} \mathrm{C}$. When $T_{\mathrm{m}}$ is altered largely, this could directly change sympathetic nervous activity. Also, afferent inputs from skin could be activated in these human studies. This may lead to different patterns of sympathetic responses than pure muscle afferent activation. In contrast, in our current report the skin covering the triceps surae muscle and femoral region was surgically separated from the muscle below, thus we have eliminated inputs from cutaneous afferents in the limb.

It should be noted that in the present report the effects of muscle blood flow on changes of $T_{\mathrm{m}}$ are not determined as muscle contraction is evoked at different temperature conditions. However, previous studies have demonstrated that blood flow directed to exercising muscles is decreased in HF (Lejemtel et al., 1986; Shoemaker et al., 1999), suggesting that blood flow is likely to contribute to attenuated $T_{\mathrm{m}}$ increase in HF as contraction is induced.

Finally, static contraction was induced by the sciatic nerve stimulation in the current study to optimize $T_{\mathrm{m}}$ and pressor responses. A study limitation is that the pressor response induced by the stimulation was possibly due, in part, to direct electrical activation of afferent nerves. However, contraction-induced increase in $T_{\mathrm{m}}$ was unlikely due to the direct stimulation of afferent nerves 
because core temperature and $T_{\mathrm{m}}$ on the contralateral leg were not altered. Also, the pressor response was closely related to change of $T_{\mathrm{m}}$ during contraction. This is important to address the issue that impaired $T_{\mathrm{m}}$ response can modify the muscle reflex in HF.

In summary, the data of present study demonstrate that contraction-induced increase in $T_{\mathrm{m}}$ is attenuated in HF animals compared with control animals, and the magnitude of the pressor response to contraction is greater as the temperature increase is lower. The impaired temperature response may alter muscle

\section{REFERENCES}

Caterina, M. J., Schumacher, M. A., Tominaga, M., Rosen, T. A., Levine, J. D., and Julius, D. (1997). The capsaicin receptor: a heat-activated ion channel in the pain pathway. Nature 389, 816-824.

Coote, J. H., Hilton, S. M., and PerezGonzalez, J. F. (1971). The reflex nature of the pressor response to muscular exercise. J. Physiol. (Lond.) 215, 789-804.

Gao, Z., Kehoe, V., Xing, J., Sinoway, L., and Li, J. (2006). Temperature modulates $\mathrm{P} 2 \mathrm{X}$ receptor-mediated cardiovascular responses to muscle afferent activation. Am. J. Physiol. Heart Circ. Physiol. 291, H1255H1261.

Gao, Z., Xing, J., Sinoway, L. I., and Li, J. (2007). P2X receptor-mediated muscle pressor reflex in myocardial infarction. Am. J. Physiol. Heart Circ. Physiol. 2292, H939-H945.

Garcia-Villalon, A. L., Padilla, J., Monge, L., Fernandez, N., Gomez, B., and Dieguez, G. (1997). Role of the purinergic and noradrenergic components in the potentiation by endothelin-1 of the sympathetic contraction of the rabbit central ear artery during cooling. Br. J. Pharmacol. 122, 172-178.

Goodwin, G. M., Mccloskey, D. I., and Mitchell, J. H. (1972). Cardiovascular and respiratory responses to changes in central command during isometric exercise at constant muscle tension. J. Physiol. (Lond.) 226, 173-190.

Guo, A., Vulchanova, L., Wang, J., Li, X., and Elde, R. (1999). Immunocytochemical localization of the vanilloid receptor 1 (VR1): relationship to neuropeptides, the $\mathrm{P} 2 \mathrm{X} 3$ purinoceptor and IB4 binding sites. Eur. J. Neurosci. 11, 946-958.

Hanna, R. L., Hayes, S. G., and Kaufman, M. P. (2002). Alpha,betamethylene ATP elicits a reflex pressor response arising from muscle in decerebrate cats. J. Appl. Physiol. 93, 834-841.

Hanna, R. L., and Kaufman, M. P. (2003). Role played by purinergic receptors on muscle afferents in evoking the exercise pressor reflex. J. Appl. Physiol. 94, 1437-1445.

Hanna, R. L., and Kaufman, M. P. (2004). Activation of thin-fiber muscle afferents by a P2X agonist in cats. J. Appl. Physiol. 96, 1166-1169.

Juneau, M., Larivee, L., and White, M. (2002). Cold temperature impairs maximal exercise performance in patients with heart failure: attenuation by acute ACE inhibitor therapy. Can. J. Cardiol. 18, 981-986.

Kaufman, M. P., and Forster, H. (1996). "Reflexes controlling circulatory, ventilatory and airway responses to exercise," in Handbook of Physiology. Exercise: Regulation and Integration of Multiple Systems, eds L. B. Rowell and J. T. Shepherd (Bethesda, MD: American Physiology Society), 381-447.

Kaufman, M. P., Longhurst, J. C., Rybicki, K. J., Wallach, J. H., and Mitchell, J. H. (1983). Effects of static muscular contraction on impulse activity of group III and IV afferents in cats. J. Appl. Physiol. 55, 105-112.

Kenny, G. P., Reardon, F. D., Zaleski, W., Reardon, M. L., Haman, F., and Ducharme, M. B. (2003). Muscle temperature transients before, during, and after exercise measured using an intramuscular multisensor probe. J. Appl. Physiol. 94, 2350-2357.

Kindig, A. E., Heller, T. B., and Kaufman, M. P. (2005). VR-1 receptor blockade attenuates the pressor response to capsaicin but has no effect on the pressor response to contraction in cats. Am. J. Physiol. Heart Circ. Physiol. 2288, H1867-H1873.

Kluess, H. A., Buckwalter, J. B., Hamann, J. J., and Clifford, P. S. (2005). Elevated temperature decreases sensitivity of P2X purinergic receptors in skeletal muscle arteries. J. Appl. Physiol. 99, 995-998.

Lejemtel, T. H., Maskin, C. S., Lucido, D., and Chadwick, B. J. (1986). Failure to augment maximal limb blood flow in response to one-leg versevere heart failure. Circulation 74, 245-251. sus two-leg exercise in patients with

afferent-mediated pressor response via temperature-sensitive $\mathrm{P} 2 \mathrm{X}$ and TRPV1 receptors. This investigation provides evidence for the role played by $T_{\mathrm{m}}$ in the exaggerated sympathetic responses to exercise in HF.

\section{ACKNOWLEDGMENTS}

This study was supported by NIH R01 HL078866, R01 HL090720, and American Heart Association Established Investigator Award $0840130 \mathrm{~N}$.

Li, J., Maile, M. D., Sinoway, A. N., and Sinoway, L. I. (2004a). Muscle pressor reflex: potential role of vanilloid type 1 receptor and acid-sensing ion channel. J. Appl. Physiol. 97, 1709-1714.

Li, J., Sinoway, A. N., Gao, Z., Maile, M. D., Pu, M., and Sinoway, L. I. (2004b). Muscle mechanoreflex and metaboreflex responses after myocardial infarction in rats. Circulation 110, 3049-3054.

Li, J., and Sinoway, L. I. (2002). ATP stimulates chemically sensitive and sensitizes mechanically sensitive afferents. Am. J. Physiol. Heart Circ. Physiol. 2283, H2636-2643.

Lind, A. (1983). "Cardiovascular adjustments to isometric contractions: static effort," in Handbook of Physiology The Cardiovascular System: Peripheral Circulation and Organ Blood Flow, eds J. T. Shepherd and S. R. Geiger (Bethesda, MD: American Physiological Society), 947-966.

Ma, Q. P. (2002). Expression of capsaicin receptor (VR1) by myelinated primary afferent neurons in rats. Neurosci. Lett. 319, 87-90.

Mark, A. L., Victor, R. G., Nerhed, C. and Wallin, B. G. (1985). Microneurographic studies of the mechanisms of sympathetic nerve responses to static exercise in humans. Circ. Res. 57, 461-469.

Matsukawa, K., Wall, P. T., Wilson, L. B., and Mitchell, J. H. (1990). Reflex responses of renal nerve activity during isometric muscle contraction in cats. Am. J. Physiol. Heart Circ. Physiol. 259, H1380-H1388.

McCloskey, D. I., and Mitchell, J. H. (1972). Reflex cardiovascular and respiratory responses originating in exercising muscle. J. Physiol. (Lond.) 224, 173-186.

Middlekauff, H. R., Nitzsche, E. U., Hoh, C. K., Hamilton, M. A., Fonarow, G. C., Hage, A., et al. (2000). Exaggerated renal vasoconstriction during exercise in heart failure patients. Circulation 101, 784-789.

Middlekauff, H. R., Nitzsche, E. U., Hoh, C. K., Hamilton, M. A., Fonarow,
G. C., Hage, A., et al. (2001). Exaggerated muscle mechanoreflex control of reflex renal vasoconstriction in heart failure. J. Appl. Physiol. 90, 1714-1719.

Mitchell, J. H., Kaufman, M. P., and Iwamoto, G. A. (1983). The exercise pressor reflex: its cardiovascular effects, afferent mechanisms, and central pathways. Annu. Rev. Physiol. 45, 229-242.

Mitchell, J. H., Reardon, W. C., and Mccloskey, D. I. (1977). Reflex effects on circulation and respiration from contracting skeletal muscle. Am. J. Physiol. 233, H374-H378.

Momen, A., Bower, D., Boehmer, J., Kunselman, A. R., Leuenberger, U. A., and Sinoway, L. I. (2004). Renal blood flow in heart failure patients during exercise. Am. J. Physiol. Heart Circ. Physiol. 2287, H2834-H2839.

Nault, M. A., Vincent, S. G., and Fisher, J. T. (1999). Mechanisms of capsaicin- and lactic acid-induced bronchoconstriction in the newborn dog. J. Physiol. (Lond.) 515, 567-578.

Ray, C. A., and Gracey, K. H. (1997). Augmentation of exercise-induced muscle sympathetic nerve activity during muscle heating. J. Appl. Physiol. 82, 1719-1725.

Ray, C. A., Hume, K. M., Gracey, K. H., and Mahoney, E. T. (1997). Muscle cooling deleys activation of the muscle metaboreflex in humans. Am J. Physiol. Heart Circ. Physiol. 242, H2436-H2441.

Shellock, F. G., Swan, H. J. C., and Rubin, S. A. (1985). Muscle and femoral vein temperatures during shortterm maximal exercise in heart failure. J. Appl. Physiol. 58, 400-408.

Shoemaker, J. K., Naylor, H. L., Hogeman, C. S., and Sinoway, L. I. (1999). Blood flow dynamics in heart failure. Circulation 99, 3002-3008.

Sinoway, L., Prophet, S., Gorman, I. Mosher, T., Shenberger, J., Dolecki, M., et al. (1989). Muscle acidosis during static exercise is associated with calf vasoconstriction. J. Appl. Physiol. 66, 429-436. 
Smith, P. J., and McQueen, D. S. (2001). Anandamide induces cardiovascular and respiratory reflexes via vasosensory nerves in the anaesthetized rat. Br. J. Pharmacol. 134, 655-663.

Smith, S. A., Williams, M. A., Mitchell, J. H., Mammen, P. A., and Garry, M. G. (2005). The capsaicin-sensitive afferent neuron in skeletal muscle is abnormal in heart failure. Circulation 111, 2056-2065.

Sterns, D. A., Ettinger, S. M., Gray, K. S., Whisler, S. K., Mosher, T. J., Smith, M. B., et al. (1991). Skeletal muscle metaboreceptor exercise responses are attenuated in heart failure. Circulation 84, 2034-2039.

Victor, R. G., Bertocci, L., Pryor, S., and Nunnally, R. (1988). Sympathetic nerve discharge is coupled to muscle cell $\mathrm{pH}$ during exercise in humans. $J$. Clin. Invest. 82, 1301-1305.
Waldrop, T. G., Eldridge, F. L., Iwamoto, G. A., and Mitchell, J. H. (1996). "Central neural control of respiration and circulation during exercise,' in Handbook of Physiology: Exercise: Regulation and Integration of Multiple Systems, eds L. B. Rowell and J. T. Shepherd (New York, NY: Oxford University Press), 333-380.

Wang, H.-J., Li, Y.-L., Gao, L., Zucker, I. H., and Wang, W. (2010). Alteration in skeletal muscle afferents in rats with chronic heart failure. J. Physiol. (Lond.) 588, 5033-5047.

Wang, Y., Toth, A., Tran, R., Szabo, T., Welter, J. D., Blumberg, P. M., et al. (2003). High-affinity partial agonists of the vanilloid receptor. Mol. Pharmacol. 64, 325-333.

Yamanouchi, T., Ajisaka, R., Sakamoto, K., Toyama, M., Saito, T., Watanabe,
S., et al. (1996). Effect of warming of exercising legs on exercise capacity in patients with impaired exercise tolerance. Jpn. Heart J. 37, 855-863.

Zahner, M. R., Li, D. P., Chen, S. R., and Pan, H. L. (2003). Cardiac vanilloid receptor 1-expressing afferent nerves and their role in the cardiogenic sympathetic reflex in rats. J. Physiol. (Lond.) 551, 515-523.

Ziganshin, A. U., Rychkov, A. V., Ziganshina, L. E., and Burnstock, G. (2002). Temperature dependency of P2 receptor-mediated responses. Eur. J. Pharmacol. 456, 107-114.

Conflict of Interest Statement: The authors declare that the research was conducted in the absence of any commercial or financial relationships that could be construed as a potential conflict of interest.

Received: 27 September 2012; accepted: 06 November 2012; published online: 26 November 2012.

Citation: Li J, Gao Z, Lu J and Xing $J$ (2012) Exaggerated pressor response in relation to attenuated muscle temperature response during contraction in ischemic heart failure. Front. Physio. 3:443. doi: 10.3389/fphys.2012.00443

This article was submitted to Frontiers in Exercise Physiology, a specialty of Frontiers in Physiology.

Copyright (C) $2012 \mathrm{Li}$, Gao, Lu and Xing. This is an open-access article distributed under the terms of the Creative Commons Attribution License, which permits use, distribution and reproduction in other forums, provided the original authors and source are credited and subject to any copyright notices concerning any third-party graphics etc. 